\title{
Characterization of plasma reflectivity response of optical glasses processed by 34 fs pulses: analysis in the context of ablation parameters
}

\author{
Andrásik Attila ${ }^{1,2}$, Flender Roland ${ }^{1}$, Budai Judit ${ }^{1}$, Szörényi Tamás ${ }^{1}$, Hopp Béla ${ }^{1}$ \\ ${ }^{1}$ Department of Optics and Quantum Electronics, University of Szeged, H-6720 Szeged, Dóm tér 9., \\ Hungary \\ ${ }^{2}$ Department of Photonics and Laser Research, Interdisciplinary Excellence Centre, University of \\ Szeged, Szeged, Hungary
}

DOI: https://doi.org/10.14232/kvantumelektronika.9.1

\section{Introduction}

One of the methods successfully applied for the improvement of the temporal contrast of ultrashort, high-intensity pulses is the plasma mirror (PM) technique [1]. An advantage of this approach is that it can effectively be utilized in the experiments applying strong-field of intensities higher than $10^{14}$ $\mathrm{W} / \mathrm{cm}^{2}$ with few cycle pulses, nevertheless, a bottleneck is the damage of the target surface due to the concomitant ablation: when working with high repetition rate, high-intensity systems [2] the target will rapidly be consumed, due to the shot-to-shot reduction of the area available. Commercially available, cheap target materials possessing appropriate plasma mirror characteristics, in best case together with the possibility of surface regeneration are needed to operate these systems. In order to allow a proper choice between attainable candidates, substantial knowledge of the response of the materials to the ablating laser pulse in general and the behavior of the transient reflectivity in particular is necessary.

All papers found in the literature are in accord in describing either the optical response or the ablation characteristics of the materials [3-18]. We did not find attempts to connect both aspects, therefore it is straightforward to expand our knowledge regarding it to properly select the most desirable targets for PM. This work was aimed at the determination of the plasma mirror related properties of three selected optical glasses, Borofloat, BK7 and B270 [19-21] through the measurement of the ablation characteristics and the evolution of the transient reflectivity when processed the glasses by single 34 fs pulses.

\section{Experimental}

The experimental setup of the single shot measurements is sketched in Fig. 1. The TeWaTi laser system of the department [22] based on a mode-locked Ti:Sapphire oscillator (Spectra-Physics Rainbow $^{\mathrm{TM}}$ ) and a home-made Ti:Sapphire chirped pulse amplifier provided pulses with $34 \pm 0.16 \mathrm{fs}$ duration and $1 \mathrm{~mJ}$ energy at $800 \mathrm{~nm}$ central wavelength with a stability at the output of the amplifier better than $1 \%$ RMS for the experiments.

Eleven holes were ablated at each pulse energy. A Veeco DEKTAK-8 stylus profilometer was used to characterize the shape of the ablated holes. The diameter and depth data reported for each energy are averages of measurements performed on the respective 11 holes. The well-known method introduced by Liu [23] was applied to determine the actual diameter of the beam on the sample surface according to the expression: 


$$
D^{2}=2 w^{2} \ln \left(F / F_{t h}\right),
$$

where $w$ is $1 / \mathrm{e}^{2}$ beam radius while $F$ and $F$ th stand for the peak and ablation threshold fluences, respectively.

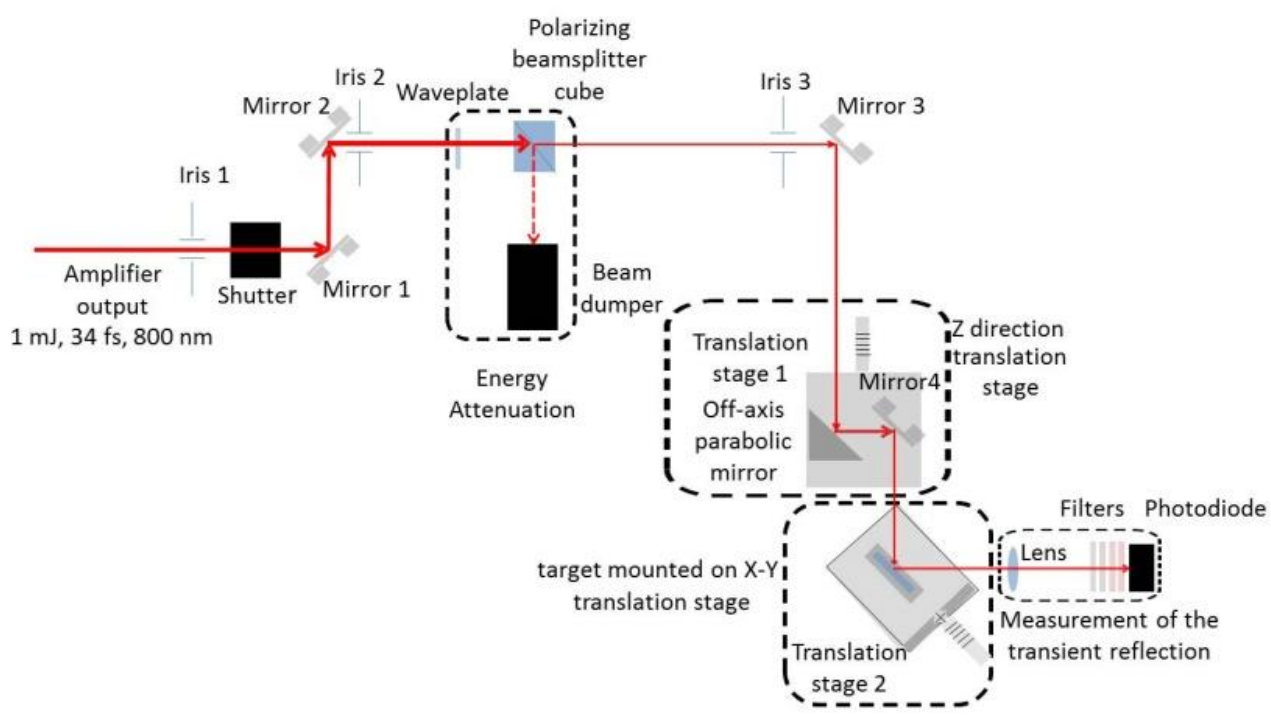

Fig. 1 Scheme of the setup (more details in [24])

\section{Results}

In Fig. 2 the diameter and the depth of the ablated holes are plotted together with the photodiode signal as a function of laser intensity for the three glass types investigated.

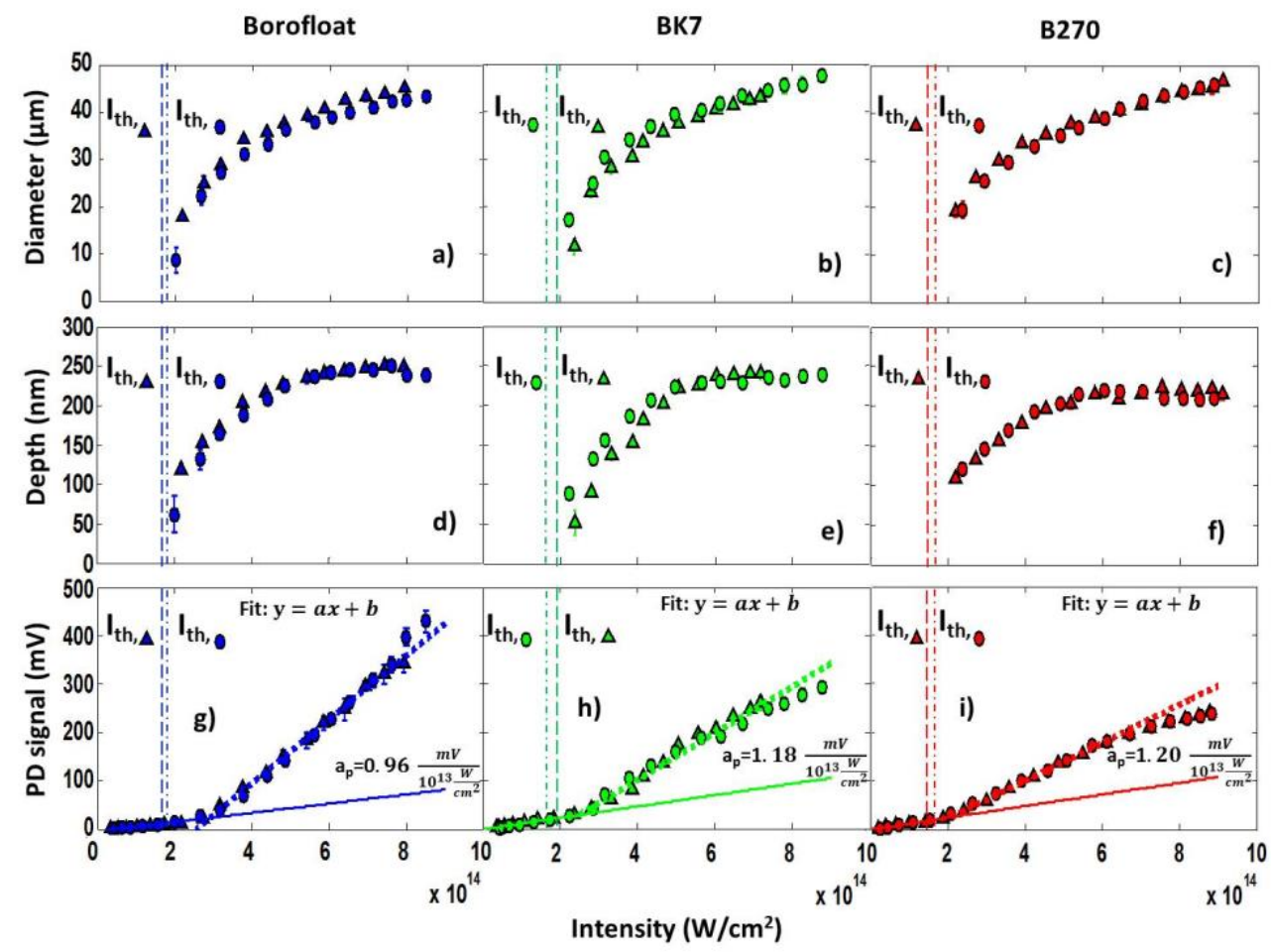

Fig. 2 Evolution of the ablation characteristics: diameter: a)-c) and the depth: d)-f), and the reflectivity g)-i) expressed in terms of photodiode recordings [more details also in [24]], process parameters: $34 \pm 0.1 \mathrm{fs}$ pulse duration and $25.5 \pm 2 \mu \mathrm{m}$ spot radius 
As seen in Fig. 2 a)-f) very similar ablation characteristics were measured for all three glasses. The ablation threshold intensities ( $\mathrm{I}_{\mathrm{th}}$ ), $1.72 \pm 0.0610^{14}, 1.89 \pm 0.1610^{14}$ and $1.75 \pm 0.0910^{14} \mathrm{~W} / \mathrm{cm}^{2}$ for Borofloat, BK7 and B270, respectively, are equal within measurement error. Above the ablation threshold logarithmic dependence was found for the diameters, while the depths increase with increasing intensity showing saturation. The deviation of the measured reflectivity from the extrapolated permanent one (dotted vs. continuous lines in Fig. 2 g)-i) marks the emergence of the plasma mirror resulting in a steep increase in the reflectivity above the threshold [24]. For Borofloat glass the slope of the increase is the greatest, reaching maximal reflectivity enhancement of $400 \%$ distinguishing Borofloat as the most promising PM target. BK7 possesses the second highest slope with $200 \%$ increase in reflectivity, while the smallest slope appears for B270, exhibiting an enhancement of $150 \%$ only. The puzzling result is that while the glasses behave similarly from the point of view of ablation, the optical responses are different.

\section{Discussion}

In a quest for finding an explanation of the differences in the reflectivities, we tried to find any link between the amount of material removed and the evolution of reflectivity. In calculating the volume of the ablated material the shape of the ablated region was assumed to be an elliptic cylinder.

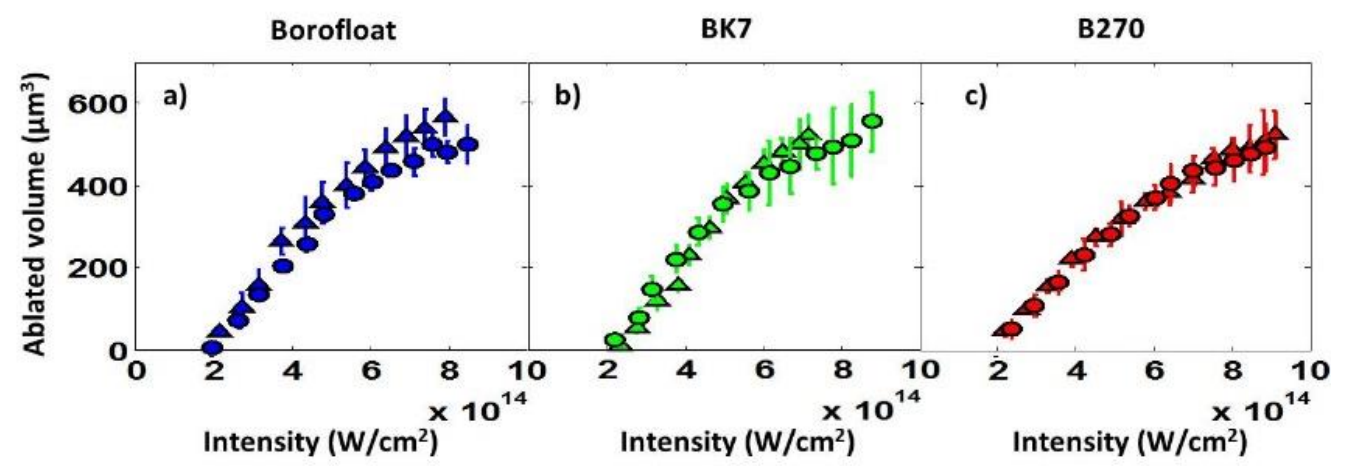

Fig. 3 The ablated volume $v s$. intensity functions for the three glass types

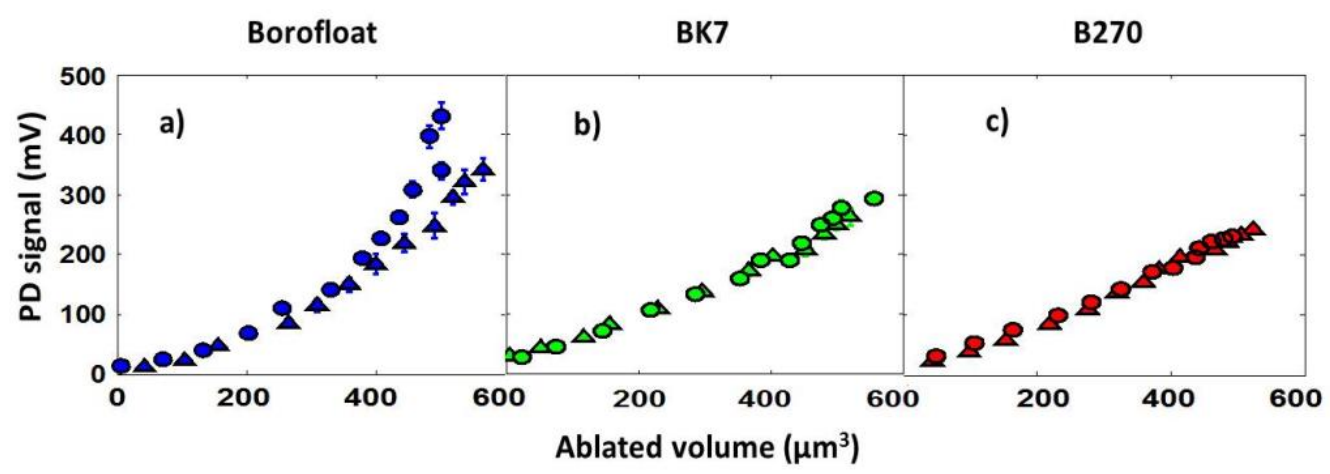

Fig. 4 The evolution of the reflected signal as a function of the ablated volume

The conclusion of the comparison is that while the three glasses behave akin from the point of view of ablation, demonstrated by the similarity of the curves in Fig. 3, their optical response depicted in Fig. 4 is different. As a corollary, it can be stated that the differences in the intensity dependence of the reflectivities cannot be correlated with the dependence of the ablated volume. 
As another approach we adopted the idea of Grehn [25] for explaining the composition dependence of the plasma mirror characteristics by the difference in the average dissociation energies of the glasses: we estimated the average number of electrons, $\mathrm{n}_{\mathrm{av}}$, participating in the formation of 1 mole glass for describing the composition dependence of the reflectivity. In Table 1 the numbers of electrons calculated according to the molar concentration of all subunits together with the composition of the respective glasses are summarized.

Table 1: Composition and the $\mathrm{n}_{\mathrm{av}}$ of the investigated glasses and fused silica

\begin{tabular}{|c|c|c|c|c|c|c|c|c|c|c|c|c|}
\hline \multirow[t]{2}{*}{ Material } & \multicolumn{11}{|c|}{ Constituents (wt\%) } & \multirow[t]{2}{*}{$\mathbf{n}_{\text {av }}$} \\
\hline & $\mathrm{SiO}_{2}$ & $\mathrm{~B}_{2} \mathrm{O}_{3}$ & $\mathrm{Na}_{2} \mathrm{O}$ & $\mathrm{K}_{2} \mathrm{O}$ & $\mathrm{CaO}$ & $\mathrm{ZnO}$ & $\mathrm{BaO}$ & $\mathrm{Al}_{2} \mathrm{O}_{3}$ & $\mathrm{As}_{2} \mathrm{O}_{3}$ & $\mathrm{TiO}_{2}$ & $\mathrm{Sb}_{2} \mathrm{O}_{3}$ & \\
\hline BOROFLOAT $^{\mathrm{a}}$ & 81 & 13 & \multicolumn{2}{|c|}{4} & - & - & - & 2 & - & - & - & 4.19 \\
\hline BK $7^{\mathbf{b}}$ & 70 & 10 & 10 & 6 & - & - & 3 & - & 1 & - & - & 3.91 \\
\hline $\mathbf{B 2 7 0} \mathbf{c}^{\mathrm{c}}$ & 69 & - & 8 & 8 & 7 & 4 & 2 & - & - & 1 & 1 & 3.48 \\
\hline
\end{tabular}

${ }^{a}$ data provided by Schott, ${ }^{b}$ data provided by Eksma Optics and [26], ${ }^{c}$ data from [27]

Good correlation was found in the variation in the time integrated plasma mirror reflectivity (400\%, $200 \%, 150 \%)$ with the $n_{a v}$ involved in the glass formation $(4.19,3.91,3.48)$ suggesting that this approach offers a plausible explanation for the differences observed in the reflectivity values of the three glasses investigated.

\section{Conclusions}

Borofloat, BK7 and B270 glasses behave similarly from the point of view of ablation with intensity thresholds within the $1.7-1.9 \times 10^{14} \mathrm{~W} / \mathrm{cm}^{2}$ domain and analogous evolution of the diameter and the depth of the ablated holes, while the optical response of the glasses is different: Borofloat is the most promising candidate for PM applications due to its highest transient reflectivity values as compared with BK7 and B270. While the difference in the behaviour of the transient reflectivities of the glasses cannot be correlated with their ablation parameters differences in the average number of electrons participating in the formation of 1 mole glass give a reasonable explanation for the differences in the reflectivities. The results of this study may help researchers and engineers to consider optical glasses as cheap alternatives to be used in PM experiments aimed at further improvement in the temporal contrast of the high repetition rate, high-intensity, ultrashort pulsed laser systems.

\section{Acknowledgements}

The project has been supported by the European Union, co-financed by the European Social Fund. EFOP-3.6.2-16-2017-00005, "Ultrafast physical processes in atoms, molecules, nanostructures and biological systems".

This work has also been supported by ELI-ALPS, ELI-HU Non-Profit Ltd. H-6720 Szeged, Dugonics tér 13; GINOP-2.3.6-15-2015-00001 and ELI_GINOP_4_0125 and The Ministry of Human Capacities, Hungary; grant 20391-3/2018/FEKUSTRAT.

The authors wish to thank Ádám Börzsönyi, Mikhail Kalashnikov and Csaba Vass from ELI-ALPS, ELI-HU Non-Profit Ltd. H-6720 Szeged, Dugonics tér 13 for valuable discussions. 


\section{References}

[1] G. Doumy, F. Quéré, O. Gobert, M. Pedrix, Ph. Martin, P. Audebert, J.C. Gauthier, J.-P. Geindre and T. Wittmann, Phys. Rev. E 69, 026402 (2004)

https://doi.org/10.1103/PhysRevE.69.026402

[2] ELI-ALPS webpage: https://www.eli-alps.hu/ (accessed at 11. 18. 2020)

[3] Ch. Ziener, P.S. Foster, E.J. Divall, C.J. Hooker, M.H.R. Hutchinson, A.J. Langley and D. Neely, J. of Appl. Phys. 93, 1 (2003) 768-770

https://doi.org/10.1063/1.1525062

[4] Y. Nomura, L. Veisz, K. Schmid, T. Wittmann, J. Wild and F. Krausz, New Journal of Physics 9 , 9 (2007)

https://doi.org/10.1088/1367-2630/9/1/009

[5] T. Wittmann, J.P. Geindre, P. Audebert, R.S. Marjoribanks, J.P. Rousseau, F. Burgy, D. Douillet, T. Lefrou, K. TaPhuoc and J.P. Chambaret, Rev. Sci. Instr. 77, 083109 (2006)

https://doi.org/10.1063/1.2234850

[6] S. Inoue, K. Maeda, S. Tokita, K. Mori, K. Teramoto, M. Hashida and S. Sakabe, Appl. Opt. 55, 21 (2016) 5647-5651

https://doi.org/10.1364/AO.55.005647

[7] B. Dromey, S. Kar, M. Zepf and P. Foster, Rev. Sci. Instr. 75, 3 (2004) 645-649

https://doi.org/10.1063/1.1646737

[8] B.C. Stuart, M.D. Feit, A. M. Rubenchik, B. W. Shore and M. D. Perry, Phys. Rev. Lett. 74, 12 (1995) 2248-2251

https://doi.org/10.1103/PhysRevLett.74.2248

[9] W.Kautek, J.Krüger, M.Lenzner, S.Sartania, C.Spielmann, F.Krausz, Appl. Phys. Lett. 69 (1996) 3146

https://doi.org/10.1063/1.116810

[10] D.Ashkenasi, A.Rosenfeld, H.Varel, M.Wahmer, E.E.B.Campbell, Applied Surface Science, 120 (1997) 65-80

https://doi.org/10.1016/S0169-4332(97)00218-3

[11] J.Krüger, W.Kautek, M.Lenzner, S.Sartania, C.Spielmann, F, Applied Surface Science, 127-129 (1998) 892-898

https://doi.org/10.1016/S0169-4332(97)00763-0

[12] M. Lenzner, J. Krüger, S. Sartania, Z. Cheng, Ch. Spielmann, G. Mourou, W. Kautek and F. Krausz, Phys. Rev. Lett. 80, 18 (1998) 4076-4079

https://doi.org/10.1103/PhysRevLett.80.4076

[13] D.Giguére, G.Olivié, F.Vidal, S.Toetsch, G.Girard, T.Ozaki, J.C, J. Opt. Soc. Am. A 24, 6 (2007) 1562-1568

https://doi.org/10.1364/JOSAA.24.001562 
[14] O. Utéza, B. Bussiére, F. Canova, J.-P. Chambaret, P. Delaporte, T. Itina and M. Sentis, Appl. Surf. Sci. 254 (2007) 799-803

https://doi.org/10.1016/j.apsusc.2007.09.046

[15] N. Sanner, O. Utéza, B. Chimier, M. Sentis, P. Lassondé, F. Légaré and J.C.Kieffer, Appl. Phys. Lett. 96, 071111 (2010)

https://doi.org/10.1063/1.3309700

[16] B. Chimier, O. Utéza, N. Sanner, M. Sentis, T. Itina, P. Lassonde, F. Légaré, F. Vidal and J.C. Kieffer, Phys. Rev. B 84, 094104 (2011)

https://doi.org/10.1103/PhysRevB.84.094104

[17] O. Utéza, N. Sanner, B. Chimier, A. Brocas, N. Varkentina, M. Sentis, P. Lassonde, F. Légaré, J.C. Kieffer, Appl. Phys. A 105, (2011) 131-141

https://doi.org/10.1007/s00339-011-6469-y

[18] M. Lenzner, J. Krüger, W. Kautek and F. Krausz, Appl. Phys. A 68, (1999) 369-371 https://doi.org/10.1007/s003390050906

[19] Borofloat specifications: https://www.pgo-online.com/intl/borofloat.html (accessed at 11. 18. 2020)

[20] BK7 specifications: https://www.pgo-online.com/intl/BK7.html (accessed at 11. 18. 2020)

[21] B720 specifications: https://www.pgo-online.com/intl/B270.html (accessed at 11. 18. 2020)

[22] Webpage of the Department of Optics and Quantumelectronics: http://opt.physx.uszeged.hu/node/45 (accessed at 25.11. 2020)

[23] J. M. Liu, Opt. Lett. 7, 5 (1982) 196-198

https://doi.org/10.1364/OL.7.000196

[24] A. Andrásik, R. Flender, J. Budai, T. Szörényi, B. Hopp, Opt. Mater. Exp. 10, 2 (2020) https://doi.org/10.1364/OME.380294

[25] M. Grehn, T. Seuthe, M. Höfner, N. Griga, C. Theiss, A. Mermillod-Blondin, M. Eberstein, H. Eichler and J. Bonse, Opt. Mat. Exp. 4, 4 (2014) 689-700

https://doi.org/10.1364/OME.4.000689

[26] H. Zhenguang, R. Srivastava and R. V. Ramaswamy, Journal of Lightwave Technology 7, 10 (1989) 1590-1596

https://doi.org/10.1109/50.39102

[27] J. Kent and M. Tsumura, US Patent US6236391B1. https://patents.google.com/patent/US6236391B1/en (accessed at 11. 18. 2020) 